BMJ Open

Sport \&

Exercise

Medicine

\title{
Acute kidney injury associated with endurance events-is it a cause for concern? A systematic review
}

\author{
LE Hodgson, ${ }^{1}$ E Walter, ${ }^{2}$ RM Venn, ${ }^{1}$ R Galloway, ${ }^{3}$ Y Pitsiladis, ${ }^{2}$ F Sardat, ${ }^{4}$ \\ LG Forni ${ }^{2,5}$
}

To cite: Hodgson LE, Walter E, Venn RM, et al. Acute kidney injury associated with endurance events-is it a cause for concern? A systematic review. BMJ Open Sport Exerc Med 2017;3:e000093. doi:10.1136/bmjsem-2015000093

Received 25 November 2015 Revised 23 March 2016 Accepted 26 March 2016

\section{(a) CrossMark}

${ }^{1}$ Department of Anaesthesia, Western Sussex Hospitals NHS Foundation Trust, West Sussex, UK

${ }^{2}$ Department of Emergency Medicine, Royal Sussex County Hospital, East Sussex, UK

${ }^{3}$ Faculty of Health and Medical Sciences, University of Surrey, Surrey, UK ${ }^{4}$ Department of Intensive Care, Surrey Peri-operative Anaesthesia Critical care collaborative Research group (SPACeR), Royal Surrey County Hospital, Surrey, UK ${ }^{5}$ The centre for sport and exercise science and medicine (SESAME), Sport and Service Management, Eastbourne, UK

Correspondence to Dr LG Forni; luiforni@nhs.net

\section{ABSTRACT}

Introduction A growing body of evidence suggests even small rises in serum creatinine ( $\mathrm{SCr}$ ) are of considerable clinical relevance. Given that participants in endurance events are exposed to potential (repeated) renal insults, a systematic review was undertaken to collate current evidence for acute kidney injury (AKI), complicating such events.

Methods A systematic review of studies and case reports meeting inclusion criteria on Medline and EMBASE (inception to October 2015). Included: studies with markers of renal function before and after endurance or ultraendurance events; case reports of severe AKI. Two reviewers assessed risk of bias using the Newcastle-Ottawa scale.

Results Eleven case report publications $(\mathrm{n}=27$ individuals) of severe AKI, were retrieved, with risk factors including systemic illness or nephrotoxic medications usually identified. From 30 studies of endurance and ultraendurance events, mean rise in $\mathrm{SCr}$ was $29( \pm 12.3) \mu \mathrm{mol} / \mathrm{L}$ after marathon or ultramarathon (17 studies, $\mathrm{n}=568$ participants) events. Where follow-up tests were conducted, $\mathrm{SCr}$ returned to baseline within 48 hours. Rises in biomarkers suggest potential parenchymal insult, rather than simply muscle breakdown. However, evidence of long-term deleterious effects is lacking.

Conclusions Raised levels of $\mathrm{SCr}$ are reported immediately after endurance events. It is not clear whether this is either clinically significant, or if repeated participation predisposes to long-term sequelae. The aetiology of severe exercise-associated AKI is usually multifactorial, with risk factors generally identified in the rare cases reported. On-site biochemistry, urine analysis and biomarkers of AKI may help identify collapsed runners who are at significant short-term risk and allow suitable follow-up.

\section{INTRODUCTION}

Endurance events continue to increase in popularity. For example, marathon participation in the USA has risen from 25000 in 1976 to over half a million in $2011 .{ }^{1}$ Participation in ultramarathons (a running event involving a distance longer than the traditional marathon length) ${ }^{2}$ is also rapidly growing. Although individuals who exercise

\section{What are the new findings}

- Twenty-seven cases of acute kidney injury (AKI) requiring hospital treatment after an endurance or ultraendurance event have been reported, with rhabdomyolysis often associated alongside at least one other identifiable risk factor.

- Across 21 studies ( $n=800$ ), including half-marathons, where pre-event and postevent serum creatinine $(\mathrm{SCr})$ levels were available, mean $\mathrm{SCr}$ increase was $25.7( \pm 11.6) \mathrm{Gmol} / \mathrm{L}$.

- Of the 17 marathons or ultramarathons studied $(n=568)$, mean SCr increase was $29( \pm 12.3)$ $\mathrm{Gmol} / \mathrm{L}$

- Non-steroidal anti-inflammatory agents appear to be a significant risk factor for AKI, though few studies in this area have been published.

- Use of renal biomarkers is of growing interest and in collapsed runners, may help identify those at high risk of significant AKI.

regularly have lower rates of disability and a mean life expectancy some 6 years longer than that of their less active contemporaries, there remain some concerns regarding potential adverse sequelae. ${ }^{3-5}$ Although sudden death among athletes attracts much publicity, it is rare and often due to a preexisting cardiomyopathy. ${ }^{6-9}$ More commonly, less severe organ damage may occur during strenuous exercise, which, if repeated over time, could have long-term significance, including renal damage, as evidenced by animal studies ${ }^{10}$ and human studies investigating cardiac imaging and enzyme markers. ${ }^{11-19}$ Though long-term evidence of harm remains scarce, recent studies have suggested an attenuation of the benefits of exercise, among those performing the most strenuous exercise, with a J-shaped or U-shaped association between all-cause mortality and running dose. $^{20-22}$

Quantifying renal damage and defining renal failure has, until recently, suffered 
from a lack of consensus definition. However this has been addressed, in part, by the adoption of the concept of acute kidney injury (AKI) which classifies renal injury on the basis of changes in measured serum creatinine $(\mathrm{SCr})$ compared with baseline values and/or changes in monitored urine output (see Appendix for AKI definitions). ${ }^{23}{ }^{24}$ This has allowed classification of patients, particularly in acute settings such as the critical care environment, allowing comparison between groups, as well as defining renal injury, which may not progress to renal failure requiring extracorporeal support. Of particular relevance is the observation that what was previously viewed as relatively trivial increases in SCr, carries an increase in acute mortality. It is now clear that renal injury, as defined by AKI, puts patients at longer-term risks of both morbidity and mortality. ${ }^{25-}$

The earliest studies reporting urinary changes on extreme exercise coincided with the seminal work by Bywaters and Beall describing the biochemical and histopathological features of crush injury observed in air raid victims during World War II which we now describe as rhabdomyolysis. ${ }^{28}$ The first documented study in athletes was in 1941 and described myoglobinuria, haematuria and albuminuria in marathon runners with the first case reports of acute renal failure complicating any sporting event reported in the $1960 \mathrm{~s}^{29}{ }^{30}$ Within the clinical arena there are numerous potential specific causes of AKI but a number of factors alone, or in combination, may exacerbate the condition. These include volume depletion secondary to inadequate fluid intake and excessive losses, rhabdomyolysis and the use of drugs such as non-steroidal anti-inflammatory drugs (NSAIDs). It follows that these factors may be common to individuals competing in endurance events with the further potential complications of climate and exercise-associated heat stroke (EHS). ${ }^{31-35}$ Therefore, AKI may be a more common complication of endurance events than anticipated. While this may seem a relatively harmless 'side-effect' of endurance events, there is now a considerable body of evidence that points to the fact that an episode of AKI complicating critical illness, for example, carries a significant risk of longer-term mortality and morbidity. Could this observation be relevant to those exhibiting an SCr rise after endurance events?

\section{Research questions}

To systematically review the frequency of AKI) associated with endurance (and ultraendurance) events; to quantify changes in SCr as a marker of renal dysfunction in endurance event studies recording values preevent and postevent. Furthermore, the review will explore mechanisms of renal dysfunction due to exercise-associated rhabdomyolysis and use of NSAIDs; finally future studies, including the use of renal biomarkers, will be addressed.

\section{Rationale and objectives}

Endurance event participation is increasing and emerging evidence suggests extreme exercise could potentially attenuate some of the benefits seen with regular exercise. AKI is an independent contributor to mortality in a large number of clinical settings. There have been case reports of significant AKI requiring hospital care following endurance events and also prospectively studied markers of renal dysfunction following endurance events, but to date, there has been no systematic review of this field. Thus, the rationale for this review was to collate all empirical evidence for AKI in endurance (and ultraendurance) events, fitting the prespecified eligibility criteria for inclusion, to answer the research questions. Explicit, systematic methods were selected with a view to minimising bias and provide reliable findings from which conclusions can be drawn. ${ }^{36} 37$

\section{METHODS}

\section{Inclusion criteria}

Adult human studies in the English language in peerreviewed journals, of endurance or ultraendurance events, examining markers of renal function; to quantify a change in SCr, studies would be included where an SCr value pre-event and immediately post the event was reported, though studies without both values would also be reported; case report studies of participants with AKI requiring hospitalisation following an endurance event.

\section{Exclusion criteria}

Research involving paediatric patients $(<18$ years old) and non-human studies; studies involving events not considered endurance (eg, <1 hour), such as track and field or football.

\section{Identification, screening, risk of bias}

We searched Medline and EMBASE for English language articles from inception to October 2015 with the text words and related Medical Subject Headings terms: 'AKI,' 'acute kidney injury,' 'Acute renal failure,' 'Renal' and 'Marathon' or 'Endurance events' as the initial set of search terms; to ensure a comprehensive literature search, reference lists were examined from retrieved articles (see Appendix for search string and PRISMA flow diagram). Titles and abstracts were screened and full articles reviewed if thought to be eligible for inclusion. Data extraction (using a pretested form), study design and quality were performed by two investigators. Discrepancies in any data extraction were discussed and assessment of a third reviewer was sought for resolution. Two reviewers assessed the risk of bias of each study using the Newcastle-Ottawa Scale. ${ }^{38}$ This scale awards a maximum of nine stars across three domains (selection, comparability of cohorts on the basis of the design and 
analysis, and outcome assessment). Studies assigned at least seven stars were deemed to be of good quality. ${ }^{39}$ For analysis of the magnitude of change in SCr we included observational studies in adults in which renal function was measured before and within hours after an endurance or ultraendurance event. Case reports of significant renal dysfunction requiring medical attention were included where the primary diagnosis was AKI.

\section{Data extraction}

Year of publication, data collection methods (retrospective or prospective), event (such as a marathon) setting (country or countries), number included, primary outcome, pre-SCr and post-SCr (where available), urine analysis, biomarkers, creatine kinase (CK) in the case reports of severe AKI; number who collapsed; and use of NSAIDs. Eleven case report studies reported a total of 27 cases of AKI. An additional 30 studies assessing markers of renal function including $\mathrm{SCr}$ changes, urine analysis and biomarkers (total number of subjects 1724) following endurance or ultraendurance events were found, of which 21 reported preevent and postevent SCr levels.

\section{RESULTS}

In 11 case report publications, 27 cases of AKI following endurance events were described (table 1). Of the events, five were marathons ${ }^{33} \quad 40-44$ and six ultramarathons. $^{30} \quad 31 \quad 45-47$ Eight participants had collapsed during the event. The majority (21/27) presented to medical attention in a delayed fashionsometimes over a week after the event. In two-thirds of cases (18/27), a history of NSAID before and/or during the event was elicited. Other risk factors included recent illness and vomiting during the events. Fifteen cases required temporary dialysis. A renal biopsy was performed on only four occasions, with features of acute tubular necrosis (ATN) in all the biopsies, suggesting an ischaemic aetiology. A diagnosis of rhabdomyolysis was made, or presumed, in $85 \%(n=23)$ of the cases. Where reported, follow-up renal function was reported to be normal, with no requirement for longterm renal replacement therapy.

A total of 30 studies ( $\mathrm{n}=1724$ participants) on renal function in endurance events were identified (table 2). These include 13 marathons, ${ }^{35}$ 48-59 10 ultramarathons, ${ }^{60-69} 2$ half-marathons, ${ }^{70} 71$ an Ironman, ${ }^{72}$ a 24hour marathon relay, ${ }^{73}$ a $60-\mathrm{km}$ mountain run $^{74}$ and 2 ultramarathon cycle races. ${ }^{75}$ Of 21 foot race events $(\mathrm{n}=800$ participants $)$ reporting pre-event and postevent SCr levels, 17 were studies of marathons or ultramarathons $(n=568$ participants). For risk of bias, 26 of the studies were deemed of good quality with a Newcastle-Ottawa Score of at least seven stars (see supplementary table for full details).

\section{Creatinine production and clearance}

A proportion of the SCr rise observed on extreme exercise reflects increases in muscle breakdown, with an enhanced solute load, rather than a fall in glomerular filtration rate (GFR). ${ }^{60}$ Hence the use of SCr to estimate GFR (eGFR) under conditions of extreme exercise should be avoided. Interestingly, a study on six marathon runners demonstrated that on the 1st day after the race, creatinine clearance actually increased, peaking on day 3 with increased urine flow rates on all 5 days postrace. ${ }^{35}$ This reflects the concept of augmented renal clearance, which is in fact a normal response to increased tubular flow. Rates of excretion and production of creatinine were closely matched on all study days. ${ }^{35}$ These results are in contrast to a study which showed no change in creatinine clearance, although inulin clearance reduced by $50 \%^{60}$ and further studies in ultramarathon cyclists where a decline in creatinine clearance of $18-25 \%$ was observed..$^{75}$ Mean fractional sodium and uric acid excretion also fell, which may indicate reduced renal perfusion, and SCr rose by $20-36 \%$, returning to normal at 24 hours.

\section{Rises in SCr}

Across 21 studies $(\mathrm{n}=800)$ where pre-event and postevent SCr levels were available, mean SCr increase was $25.7( \pm 11.6) \mu \mathrm{mol} / \mathrm{L}$. Of the 17 marathons or ultramarathons described $(\mathrm{n}=568)$, mean SCr increase was 29 $( \pm 12.3) \mu \mathrm{mol} / \mathrm{L}$, above the threshold for AKI stage $1 .{ }^{24}$ Though most studies demonstrated an increase in $\mathrm{SCr}$ immediately following the event, in the 13 studies reporting recovery of function, as described by changes in SCr, all had returned to baseline or were improving within 48 hours (table 2). Studies involving half-marathons reported smaller increases in SCr levels, with eGFR recovering within 6 hours in one study. ${ }^{70}$ In two recent extended ultraendurance races over weeks to months, no contestants developed AKI, despite significant rises in CK, suggesting repetitive, relatively lower intensity exercise, despite the large total distance covered, may mean that cumulative damage does not occur in these events. ${ }^{77} 78$ A recent study by Lipman et $a l^{66}$ also supports this, documenting rises in SCr, with 45-67\% meeting RIFLE criteria 'Risk' and 7-13\% 'Injury' (see Appendix for RIFLE criteria) between stages of a multistage ultramarathon race, but found a rapid reduction back to baseline prior to the following stage. Christensen $e t a l^{68}$ investigated renal function up to 48 hours following a $78-\mathrm{km}$ ultramarathon at moderate altitude $(\sim 2400 \mathrm{~m})$ by 10 runners from the Mexican Tarahumara tribe, who have maintained the once widespread tradition of ultradistance running, from a young age. The authors found immediate postrace $\mathrm{SCr}$ was not significantly elevated, though an increase of $25 \%$ was noted by 6 hours, with a subsequent fall-back to baseline at 48 hours. Follow-up for the 30 studies did not extend beyond more than a few 


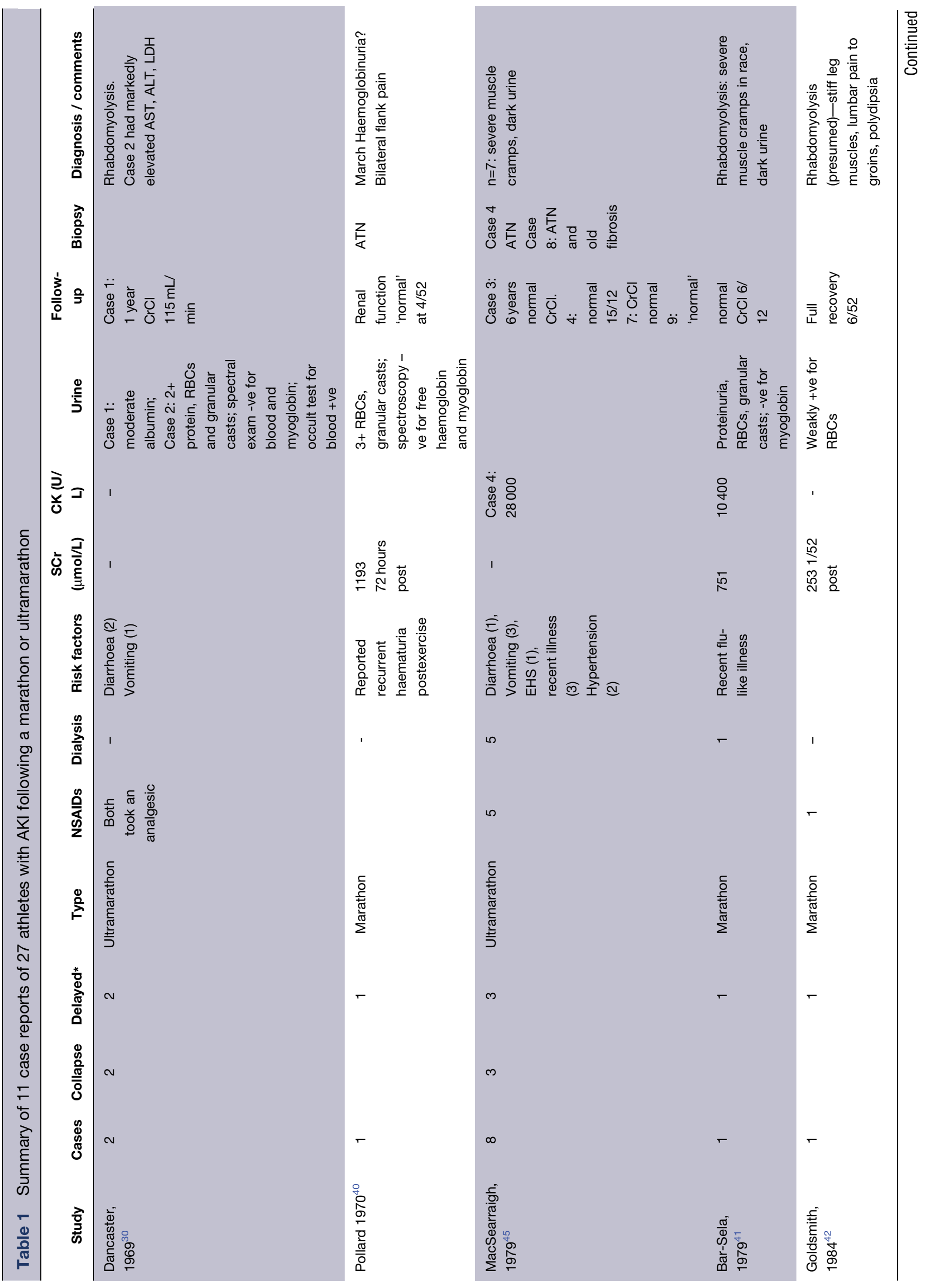




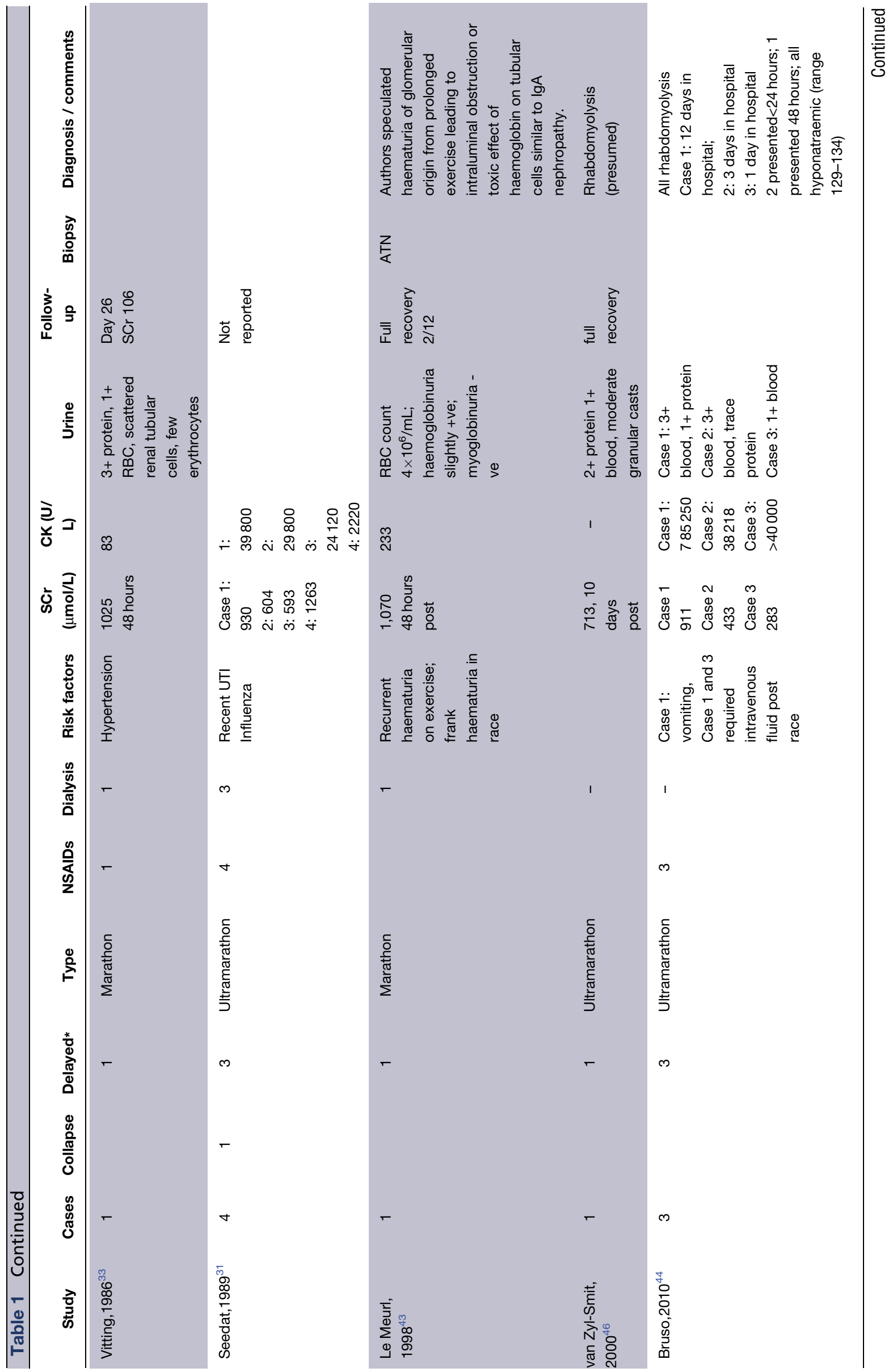


days, thus conclusions around the effects of recurrent participation in such events cannot be made.

Studies examining the use of NSAIDs

In the studies where NSAID use was reported, $23 \%$ $(\mathrm{n}=312 / 1359)$ of participants admitted to NSAID usage. Two studies, one of marathon runners ${ }^{53}$ and another of 330 Ironman participants, ${ }^{72}$ reported a significant increase in SCr in the participants using an NSAID. In contrast, a prospective ultramarathon study Dumke et $a l^{69}$ studied a group taking an NSAID $(n=29)$ and a group not $(n=25)$ with no significant difference in SCr between groups.

\section{Studies on collapsed runners}

Two studies specifically reported on SCr levels in runners who had collapsed. ${ }^{51} 61$ In the first, 36 collapsed runners had mean postrace SCr of 141 $( \pm 26)$ vs $123( \pm 23) \mu \mathrm{mol} / \mathrm{L}$ in a control group of 60 runners $(\mathrm{p}<0.01) .{ }^{51}$ Within 24 hours, mean SCr had fallen to $104( \pm 13) \mu \mathrm{mol} / \mathrm{L}$ compared with $95( \pm 13)$ $\mu \mathrm{mol} / \mathrm{L}$ in the control group $(\mathrm{p}<0.05)$. Irving et al included eight ultra-marathon runners who had collapsed with hyponatraemia $(<130 \mathrm{mmol} / \mathrm{L})$ requiring hospital admission. Their postrace mean $\mathrm{SCr}$ level was $89 \mu \mathrm{mol} / \mathrm{L}$ vs $104 \mu \mathrm{mol} / \mathrm{L}$ in a control group $(\mathrm{n}=18)$. A repeat test on 'recovery' showed mean SCr levels had reduced to $68 \mu \mathrm{mol} / \mathrm{L}(\mathrm{p}<0.05)$ and 78 $\mu \mathrm{mol} / \mathrm{L}(\mathrm{p}<0.01)$, respectively. ${ }^{61}$

\section{Other markers of possible renal dysfunction}

The SCr provides the basis by which chronic kidney disease (CKD) is defined, with the eGFR allowing stratification of patients with CKD. However, the use of $\mathrm{SCr}$, and derived eGFR equations implies that creatinine production rate is at a steady state and hence, more accurately reflects the GFR. This is not the case in many acute clinical scenarios and clearly not during and after, extreme exercise. The use of other candidate molecules as potential markers of renal dysfunction is emerging as a potential avenue to investigate the true significance of endurance events on renal functionparticularly in the higher-risk group of participants who have collapsed. Any potentially useful candidate AKI biomarker(s) should ideally fulfil several criteria. These include, the provision of information above that currently available in determining abnormal renal function and also distinguish prerenal azotaemia from intrinsic renal disease. This is of particular relevance in extreme exercise where a prerenal component may predominate. If biomarkers could aid prognostication regarding potential renal recovery this also would be beneficial. Most recently identified biomarkers of AKI can be broadly classified into three groups: low molecular weight proteins which undergo glomerular filtration and hence reflect glomerular function, or markers of tubule damage, such as enzymes released 


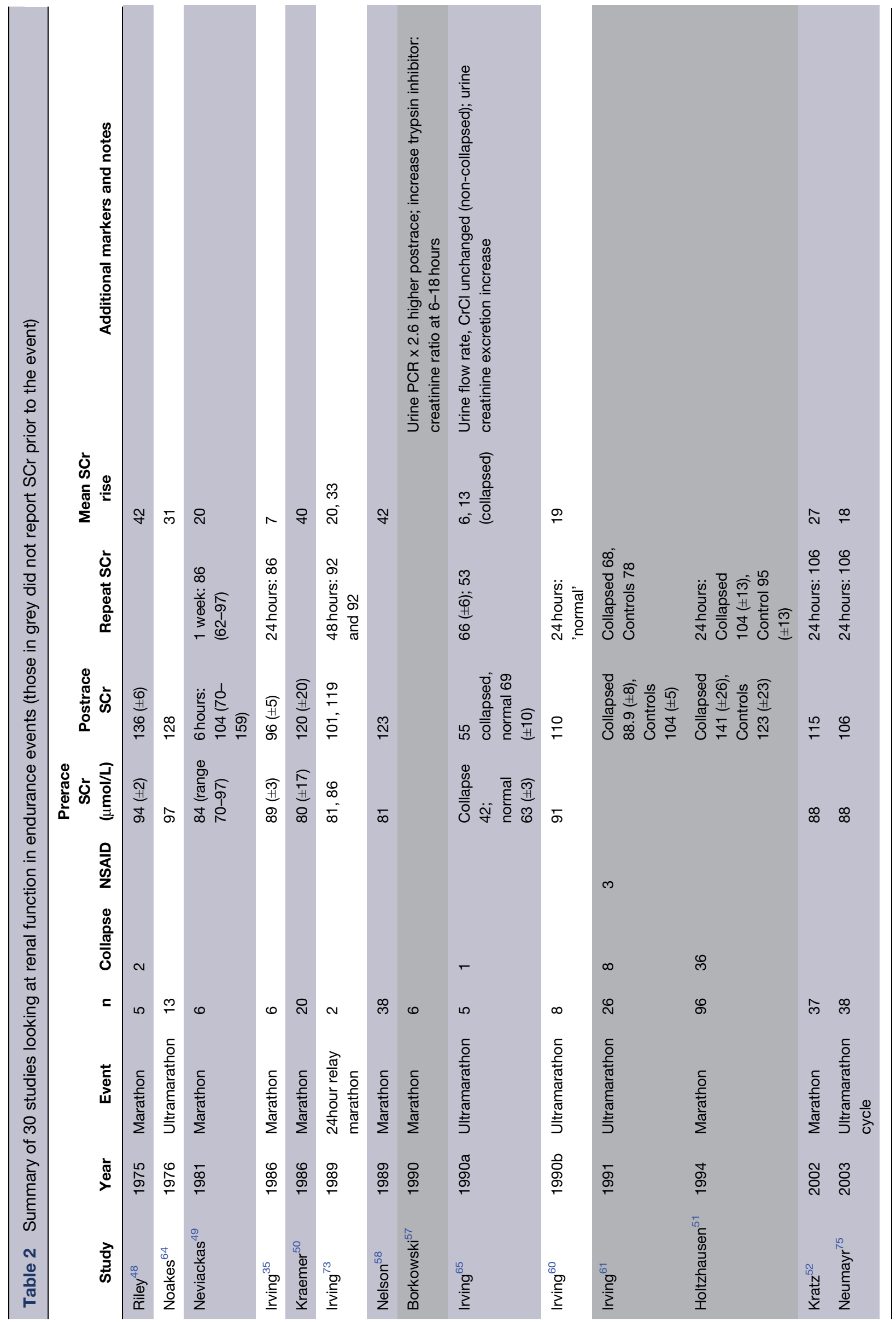




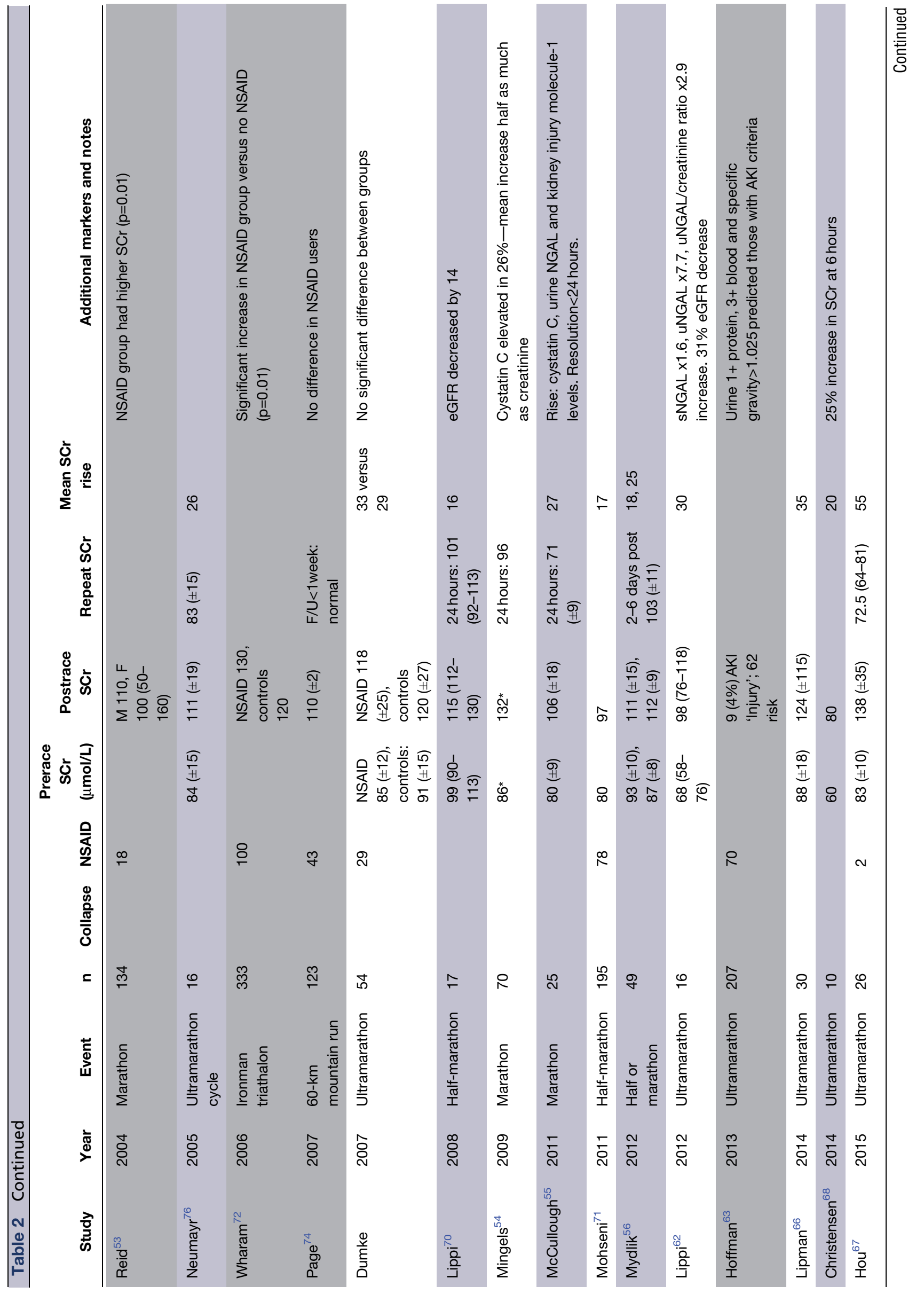


into the urine after tubular cell injury, or inflammatory mediators either released by renal cells, or by infiltrating inflammatory cells.

Cystatin $\mathrm{C}$ is an effective biomarker of glomerular filtration, correlates well with GFR and is independent of muscle mass. ${ }^{79}$ Indeed, studies on renal function following strenuous exercise demonstrated that the mean cystatin $\mathrm{C}$ rise was half that of the mean SCr rise in runners following a marathon. ${ }^{54}$ Further studies demonstrated a correlation between cystatin $\mathrm{C}$ and $\mathrm{SCr}$ rise immediately after a marathon, with $40 \%$ of participants reaching the creatinine criteria for stage 1 AKI. ${ }^{55}$ Participants also demonstrated a rise in urinary neutrophil gelatinase-associated lipocalin (NGAL) and urinary kidney injury molecule-1 (KIM-1), suggesting early tubular dysfunction, although all biomarkers returned to baseline within 24 hours. Hewing ${ }^{59}$ in a Berlin marathon study $(n=167)$, found cystatin-based GFR was significantly decreased by RIFLE criteria, with $30 \%$ demonstrating a decrease of $>25 \%$ (risk) and $8 \%$ a decrease $>50 \%$ (injury). All parameters returned to baseline ranges within a 2-week follow-up period.

NGAL is a $25 \mathrm{kDa}$ acute phase protein largely produced by the kidney tubule, though it is also upregulated in other pathological conditions. In a study of 16 ultramarathon runners ${ }^{62}$ mean increase in SCr was $38 \%$, with a significant increase in serum NGAL, urinary NGAL, as well as the urinary NGAL/creatinine ratio. Other studies have demonstrated increases in the urine protein:creatinine ratio $6-18$ hours postrace. ${ }^{57}$ In a study on 152 runners in a $161 \mathrm{~km}$ ultramarathon, $34 \%$ met AKI criteria, with those demonstrating more significant degrees of injury having a significantly higher CK concentration. In addition, urinalysis tests that were positive for at least $1+$ protein, $3+$ blood and specific gravity $\geq 1.025$ predicted those meeting the injury criteria with high sensitivity. The authors commented that using this simple test could be a useful screening test to identify those at highest rise. ${ }^{63}$

The diagnostic utility of most of the biomarkers described to date to diagnose AKI prior to elevations in SCr is variable. This is due, in part, to clinical studies being hampered by diverse patient populations with differing comorbidities, the timing of the measurements and chosen cut-off values. More recently, studies have emerged using two biomarkers associated with cell cycle arrest, namely insulin-like growth factorbinding protein 7 and tissue inhibitor of metalloproteinases-2 .80 81 The concentrations of these two proteins was found to be in the urine of patients at high risk of AKI from a variety of aetiologies. Initial studies seem to suggest that these perform better than other known markers within this patient cohort; the mechanism of which may be an 'alarm signal' raised by the renal tubules, in response to stress. Furthermore, recent data imply that the presence of these biomarkers in the context of AKI may predict a worse prognosis in the critically ill, so perhaps they may be able to identify a 
group of athletes who may require closer follow-up (see figure 1 for a pathway outlining the aetiology of endurance exercise related renal dysfunction and potential utility of a biomarker to risk stratify participants). ${ }^{82}$

\section{DISCUSSION}

Pathophysiological effects of exercise on renal function

Increased blood flow to the muscles during exercise is accompanied by decreased renal blood flow proportional to extent and duration of the physical effort. ${ }^{83}$ In moderate exercise, renal blood flow may fall to $25 \%$ of the resting value, although GFR is preserved through an increase in the filtration fraction, which may double, limiting the transfer of metabolites or substances through the glomeruli and reducing the extent of exercise proteinuria. ${ }^{84-88}$ Extreme exercise however, may decrease GFR by up to $50 \%$, through increased release of catecholamines, AVP and activation of the renin-angiotensin-aldosterone system. ${ }^{89-91}$ Whether prolonged reduction of renal blood flow is associated with intrinsic renal injury is uncertain and the clarification of this issue to date has been limited by the lack of a reliable biomarker. Despite evidence that AKI may progress to CKD, of the reported cases of AKI following an endurance event, we could find no documented case of progression to CKD. From the studies involving endurance events, $\mathrm{SCr}$ increases significantly, although whether this represents a significant insult to the kidney is not clear.

\section{Extreme exercise-specific risk factors for AKI}

Despite rises in measured SCr, the evidence for AKI requiring medical intervention is sparse. However, there are several conditions whereby the effects of extreme exercise on the kidney can be exacerbated. These include the development of pigment nephropathy, the use of NSAIDs and exertional heat stroke (EHS).

\section{Pigment nephropathy}

Rhabdomyolysis causes AKI through the direct toxic effect of myoglobin on the renal tubule. Severe exertion causes the syndrome through a combination of mechanical and thermal muscle injuries. Both intensity and duration of exercise are related to muscle damage in a dose-response manner. ${ }^{92-94} \mathrm{CK}$ is the most sensitive marker of myocyte injury with levels at least five times above the upper limit of normal required to fulfil the diagnosis of rhabdomyolysis, although absolute levels do not correlate well with disease severity, nor risk of renal failure. ${ }^{95} 96$ AKI is common where rhabdomyolysis complicates critical illness, whereas in exercise-related rhabdomyolysis, AKI is rare. For example, Skenderi et al, ${ }^{97}$ found markedly raised CK levels in 39 runners after an ultra-marathon, yet none required medical assistance, nor developed AKI. Rhabdomyolysis with AKI has been observed following exercise when extreme physical exertion has been performed under conditions of high temperature, dehydration with, or without acute illness. ${ }^{98} 99$

\section{Non-steroidal anti-inflammatory drugs}

NSAIDs inhibit cyclo-oxygenase, thereby preventing prostaglandin synthesis (PGs). PGs enhance renal perfusion through vascular dilatation and promote diuresis and natriuresis through inhibition of sodium transport in the thick ascending limb of loop of Henle and the collecting ducts. ${ }^{100}{ }^{101} \mathrm{PGE}_{1}$ tends to antagonise the action of vasopressin and $\mathrm{PGI}_{2}$ in concert with $\mathrm{PGE}_{2}$, serves to maintain the GFR. ${ }^{102}{ }^{103}$ In healthy subjects, basal renal vasoconstrictor tone is low and the vasodilation produced by $\mathrm{PGs}$ is not required for normal renal function. ${ }^{104}{ }^{105}$ In disease states however, where increased sympathetic outflow to the kidney may be found, PGs vasodilate the renal vascular bed and ensure adequate renal blood supply. Therefore inhibition of PG synthesis may result in the unopposed vasoconstrictive action of leukotrienes, angiotensin II, vasopressin, endothelin and catecholamines. Indeed, NSAIDs have been shown to decrease renal blood flow with exercise, although this did not translate into significant differences in GFR (measured by inulin clearance) when subjects exercised at $80 \% \mathrm{VO}_{2 \max }$ for $30 \mathrm{~min} .{ }^{106}$ Olsen et al studied healthy volunteers undergoing submaximal exercise with and without indomethicin. ${ }^{107}$ This NSAID significantly inhibited renal PG synthesis and renin release. Overall renal functional response to exercise remained unchanged, possibly because of inhibition of renin-mediated angiotensin II generation and cyclo-oxygenase-1 mediated thromboxane $\mathrm{A}_{2}$ synthesis.

Given that NSAIDs may have deleterious effects on renal blood flow, does the use of these agents translate into a higher risk of AKI in subjects undergoing extreme exercise? To date, few studies have addressed the impact of NSAID use on renal function after an endurance event, compared with those not taking NSAIDs. Reid et al found a significant mean increase in creatinine in the NSAID group compared with those not taking an NSAID in marathon runners. ${ }^{53}$ Wharam et $a l^{72}$ in an Ironman study, reported a statistically significant difference in SCr of $10 \mu \mathrm{mol} / \mathrm{L}$ among the NSAID group, though this may not suggest a clinically significant difference. In contrast, Dumke et al, in a prospective study, found no significant difference in markers of renal function between those who did, and did not, use NSAIDs. ${ }^{69}$ However, our review data presented here show that 18 of the 27 case reports $(67 \%)$ of renal failure (requiring hospital treatment) following an endurance event had taken an NSAID, which is in keeping with the widespread use of these agents. With regard to pigment nephropathy, conflicting results are found with studies showing an increase, no effect or a decrease in markers of muscle damage. ${ }^{108-110}$ 


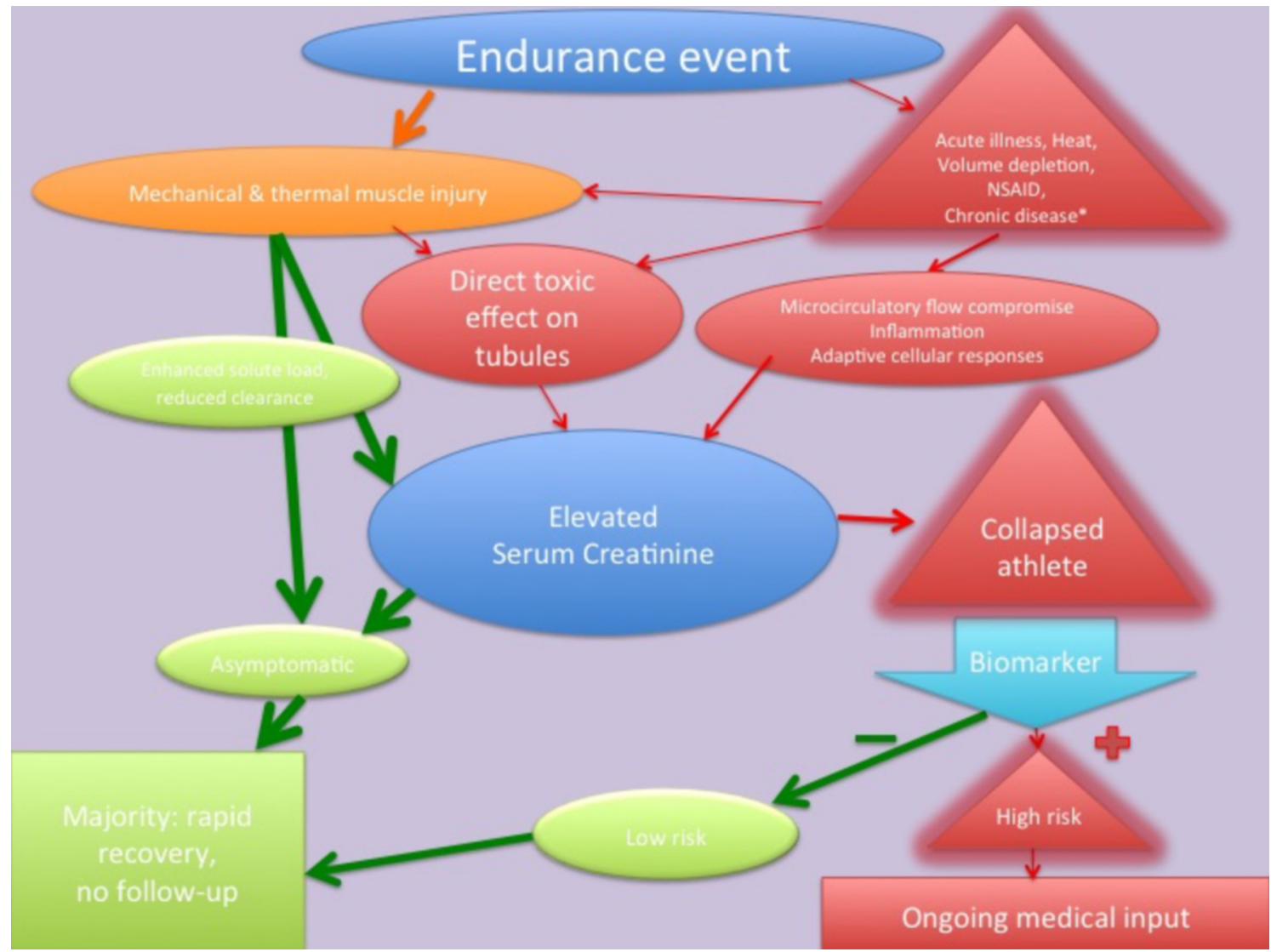

Figure 1 Pathway outlining the aetiology of endurance exercise related renal dysfunction and potential utility of a biomarker to risk stratify participants. ${ }^{*}$ Chronic disease such as hypertension, diabetes, chronic kidney disease. NSAID, non-steroidal anti-inflammatory drug.

\section{Exertional heat stroke}

AKI is often found in patients with EHS, which can be fatal. ${ }^{111-114}$ In addition to rhabdomyolysis and volume depletion, alterations in circulating vasoactive mediators are implicated. ${ }^{115}$ Subsequent multiorgan injury results from a complex interplay between the cytotoxic effect of the heat and the inflammatory and coagulation responses of the host. ${ }^{116}$ There have been recent guidelines developed to reduce the risk of EHS particularly in warm environments from the perspective of the athlete (including heat acclimatisation, initiate competition in an euhydrated state and minimise dehydration) and event organisers (provide shaded areas, cooling and rehydration facilities, and suitably schedule events). ${ }^{117}$

\section{Exercise-induced AKI developing after anaerobic exercise}

Exercise-induced AKI developing after anaerobic exercise (coined ALPE) is an uncommon syndrome differing from rhabdomyolysis by normal or slightly elevated serum muscle enzymes associated with muscle damage and the presence of severe loin pain. Vasoconstriction of intrarenal arteries within the kidney is thought to be the cause and studies using CT demonstrate multiple wedge-shaped areas of contrast enhancement in keeping with patchy vasoconstriction of the renal vessels. It is thought that vascular spasm accounts for the pain reported. ${ }^{18-121}$ Interestingly, a recent review of 118 cases of ALPE demonstrated a high percentage of subjects had hypouricaemia which can be associated with exercise-induced AKI. ${ }^{118}$

\section{Limitations of the study}

To the authors' knowledge this is the first systematic review to address case reports of AKI in association with endurance events and provides evidence from a number of observational studies, as to the effects of endurance events on SCr. The studies included were heterogenous (though most scored highly on a risk of bias assessment) and none included a significant time of follow-up, nor was any study found looking at the effect of performing multiple endurance events, over a period of years. Newer studies with renal biomarkers have suggested an increased SCr may be due to more than just an enhanced solute load and reduced clearance. However, firm conclusions as yet cannot be drawn from the available evidence. The case reports of significant renal injury by their retrospective nature have limitations, though the relatively large number with similar histories (acute illness, collapse, nephrotoxic drug use and delayed presentations) allows some interesting information to be drawn. 


\section{CONCLUSIONS}

AKI requiring medical attention associated with extreme exercise is rare, with only 27 cases identified in this review, usually thought to be primarily due to rhabdomyolysis. Most cases had a number of risk factors for AKI, including the use of NSAIDs and an intercurrent illness or gastrointestinal upset. The majority presented in a delayed fashion, emphasising the need for awareness of this rare complication, particularly among participants who have become unwell during an event. It is likely that less severe cases of AKI with rhabdomyolysis go unreported and self-resolve. In contrast, an SCr rise after a marathon or ultra-marathon is common, with an average rise of $29( \pm 12.3) \mu \mathrm{mol} / \mathrm{L}$, which appears to improve rapidly. However, there are few studies of collapsed runners with deranged renal function and their longer-term follow-up. Furthermore, in light of gathering evidence that strenuous exercise could have some adverse effects, it is not clear whether repeated participation in such events may eventually lead to significant longterm renal dysfunction. New biomarkers may be able to differentiate between an increased SCr due to an enhanced solute load and reduced clearance, rather than direct tubular damage. As such, their use in collapsed runners, who represent a higher-risk group, may be of future interest, as an addition to routine point-of-care testing.

\section{RECOMMENDATIONS}

Below are our pragmatic recommendations:

1. All marathon runners (or other endurance runners) should be given advice regarding the avoidance of NSAIDs, monitoring of urine volume and colour and the importance of adequate hydration.

2. Participants with pre-existing risk factors (for example, pre-existing renal dysfunction, hypertension and diabetes) should be made aware of the potential dangers of NSAIDs and systemic upset (such as vomiting) around the time of the event.

3. Runners who have collapsed during or at the end of a marathon, should have their observations recorded and basic investigations performed (including a urine dip and basic biochemistry); abnormal results should be followed up within a suitable time frame, according to local resources.

4. Future research could focus on biomarkers that more specifically reflect renal dysfunction, to help identify those at most risk and allow follow-up, where dysfunction has been found.

Contributors LH: conception, design, literature search, risk of bias assessment, write-up. EW: conception, design, literature search, write-up. RV: conception, design, literature search, write-up. RG: conception, literature search, write-up. YP: conception design, write-up. FS: literature search, writeup. LF: conception design, literature search, risk of bias assessment, write-up.

Competing interests None declared.
Provenance and peer review Not commissioned; internally peer reviewed.

Open Access This is an Open Access article distributed in accordance with the Creative Commons Attribution Non Commercial (CC BY-NC 4.0) license, which permits others to distribute, remix, adapt, build upon this work noncommercially, and license their derivative works on different terms, provided the original work is properly cited and the use is non-commercial. See: http:// creativecommons.org/licenses/by-nc/4.0/

(C) Article author(s) (or their employer(s) unless otherwise stated in the text of the article) 2017. All rights reserved. No commercial use is permitted unless otherwise expressly granted.

\section{REFERENCES}

1. RunningUSA. Annual Marathon Report, Running USA. 2014.

2. Zaryski C, Smith DJ. Training principles and issues for ultraendurance athletes. Curr Sports Med Rep 2005;4:165-70.

3. Chakravarty EF, Hubert HB, Lingala VB, et al. Reduced disability and mortality among aging runners: a 21-year longitudinal study. Arch Intern Med 2008;168:1638-46.

4. Sarna S, Sahi T, Koskenvuo M, et al. Increased life expectancy of world class male athletes. Med Sci Sports Exerc 1993;25:237-44.

5. Schnohr $\mathrm{P}$, Marott $\mathrm{JL}$, Lange $\mathrm{P}$, et al. Longevity in male and female joggers: the Copenhagen City Heart Study. Am J Epidemiol 2013;177:683-9.

6. Pugh A, Bourke JP, Kunadian V. Sudden cardiac death among competitive adult athletes: a review. Postgrad Med $J$ 2012;88:382-90.

7. Sharma S, Whyte G, McKenna WJ. Sudden death from cardiovascular disease in young athletes: fact or fiction? $\mathrm{Br} \mathrm{J}$ Sports Med 1997;31:269-76.

8. Kim JH, Malhotra R, Chiampas G, et al; Race Associated Cardiac Arrest Event Registry (RACER) Study Group. Cardiac arrest during long-distance running races. N Engl J Med 2012;366:130-40.

9. Corrado D, Basso C, Thiene G. Sudden cardiac death in athletes: what is the role of screening? Curr Opin Cardiol 2012;27:41-8

10. Benito B, Gay-Jordi G, Serrano-Mollar A, et al. Cardiac arrhythmogenic remodeling in a rat model of long-term intensive exercise training. Circulation 2011;123:13-22.

11. Scharhag J, George K, Shave R, et al. Exercise-associated increases in cardiac biomarkers. Med Sci Sports Exerc 2008; $40: 1408-15$

12. Middleton N, George K, Whyte G, et al. Cardiac troponin T release is stimulated by endurance exercise in healthy humans. J Am Coll Cardiol 2008;52:1813-4.

13. Rifai N, Douglas PS, O'Toole M, et al. Cardiac troponin T and I, echocardiographic [correction of electrocardiographic] wall motion analyses, and ejection fractions in athletes participating in the Hawaii Ironman Triathlon. Am J Cardiol 1999;83:1085-9.

14. Neilan TG, Januzzi JL, Lee-Lewandrowski E, et al. Myocardial injury and ventricular dysfunction related to training levels among nonelite participants in the Boston marathon. Circulation 2006;114:2325-33.

15. Shave R, Baggish A, George K, et al. Exercise-induced cardiac troponin elevation: evidence, mechanisms, and implications. J Am Coll Cardiol 2010;56:169-76.

16. Neumayr G, Gaenzer H, Pfister R, et al. Plasma levels of cardiac troponin I after prolonged strenuous endurance exercise. Am J Cardiol 2001;87:369--71.

17. Scherr J, Braun S, Schuster T, et al. 72-h kinetics of high-sensitive troponin T and inflammatory markers after marathon. Med Sci Sports Exerc 2011;43:1819-27.

18. Neilan TG, Yoerger DM, Douglas PS, et al. Persistent and reversible cardiac dysfunction among amateur marathon runners. Eur Heart J 2006;27:1079-84.

19. Trivax JE, Franklin BA, Goldstein JA, et al. Acute cardiac effects of marathon running. J Appl Physiol 2010;108:1148-53.

20. Lee DC, Pate RR, Lavie CJ, et al. Leisure-time running reduces allcause and cardiovascular mortality risk. J Am Coll Cardiol 2014;64:472-81.

21. Schnohr P, O'Keefe JH, Marott JL, et al. Dose of jogging and longterm mortality: the Copenhagen City Heart Study. J Am Coll Cardiol 2015;65:411-9.

22. Mons $\mathrm{U}$, Hahmann $\mathrm{H}$, Brenner $\mathrm{H}$. A reverse J-shaped association of leisure time physical activity with prognosis in patients with stable coronary heart disease: evidence from a large cohort with repeated measurements. Heart 2014;100:1043-9. 
23. Bellomo R, Ronco C, Kellum JA, et al; Acute Dialysis Quality Initiative workgroup. Acute renal failure - definition, outcome measures, animal models, fluid therapy and information technology needs: the Second International Consensus Conference of the Acute Dialysis Quality Initiative (ADQI) Group. Crit Care 2004;8:R204-12.

24. KDIGO clinical practice guideline for acute kidney injury. Kidney Int 2012;2(Suppl 1):1-136.

25. Chertow GM, Burdick E, Honour M, et al. Acute kidney injury, mortality, length of stay, and costs in hospitalized patients. J Am Soc Nephrol 2005;16:3365-70.

26. Lassnigg A, Schmid ER, Hiesmayr M, et al. Impact of minimal increases in serum creatinine on outcome in patients after cardiothoracic surgery: do we have to revise current definitions of acute renal failure? Crit Care Med 2008;36:1129-37.

27. Newsome BB, Warnock DG, McClellan WM, et al. Long-term risk of mortality and end-stage renal disease among the elderly after small increases in serum creatinine level during hospitalization for acute myocardial infarction. Arch Intern Med 2008;168:609-16.

28. Bywaters EG, Beall D. Crush Injuries with Impairment of renal Function. Br Med J 1941;1:427-32.

29. Ra B. Urinary findings before and after a marathon race. $N$ Engl J Med 1941;225:801-2.

30. Dancaster CP, Duckworth WC, Roper CJ. Nephropathy in marathon runners. S Afr Med J 1969;43:758-60.

31. Seedat YK, Aboo N, Naicker $S$, et al. Acute renal failure in the "Comrades Marathon" runners. Ren Fail 1989;11:209-12.

32. Schiff HB, MacSearraigh ET, Kallmeyer JC. Myoglobinuria, rhabdomyolysis and marathon running. Q J Med 1978;47:463-72.

33. Vitting KE, Nichols NJ, Seligson GR. Naproxen and acute renal failure in a runner. Ann Intern Med 1986;105:144.

34. Whitworth JA, Wolfman MJ. Fatal heat stroke in a long distance runner. Br Med J 1983;287:948.

35. Irving RA, Noakes TD, Irving GA, et al. The immediate and delayed effects of marathon running on renal function. $J$ Urol 1986;136:1176-80

36. Antman EM, Lau J, Kupelnick B, et al. A comparison of results of meta-analyses of randomized control trials and recommendations of clinical experts. treatments for myocardial infarction. JAMA 1992;268:240-8

37. Oxman AD, Guyatt GH. The science of reviewing research. Ann N $Y$ Acad Sci 1993;703:125-33.

38. Wells G, Shea B, Peterson J, et al. The Newcastle-Ottawa scale (NOS) for assessing the quality of nonrandomised studies in metaanalyses.

39. Patra J, Bhatia M, Suraweera W, et al. Exposure to second-hand smoke and the risk of tuberculosis in children and adults: a systematic review and meta-analysis of 18 observational studies. PLoS Med 2015;12:e1001835.

40. Pollard TD, Weiss IW. Acute tubular necrosis in a patient with march hemoglobinuria. N Engl J Med 1970;283:803-4.

41. Bar-Sela S, Tur-Kaspa R, Eliakim M. Rhabdomyolysis and acute renal failure in a marathon runner in israel. Isr J Med Sci 1979;15:464-6.

42. Goldsmith HJ. Acute renal failure after a marathon run. Lancet 1984;1:278-9.

43. Le Meur Y, Paraf F, Szelag JC, et al. Acute renal failure in a marathon runner: role of glomerular bleeding in tubular injury. Am J Med 1998;105:251-2.

44. Bruso JR, Hoffman MD, Rogers IR, et al. Rhabdomyolysis and hyponatremia: a cluster of five cases at the 161-km 2009 western States endurance Run. Wilderness Environ Med 2010;21:303-8.

45. MacSearraigh ET, Kallmeyer JC, Schiff HB. Acute renal failure in marathon runners. Nephron 1979;24:236-40.

46. van Zyl-Smit R, Mills P, Vogelpoel L. Unrecognized acute renal failure following the comrades marathon. S Afr Med J 2000;90:39-40.

47. Boulter J, Noakes TD, Hew-Butler T. Acute renal failure in four comrades marathon runners ingesting the same electrolyte supplement: coincidence or causation? S Afr Med J 2011;101:876-8

48. Riley WJ, Pyke FS, Roberts AD, et al. The effect of long-distance running on some biochemical variables. Clin Chim Acta 1975;65:83-9.

49. Neviackas JA, Bauer JH. Renal function abnormalities induced by marathon running. South Med J 1981;74:1457-60.

50. Kraemer RR, Brown BS. Alterations in plasma-volume-corrected blood components of marathon runners and concomitant relationship to performance. Eur J Appl Physiol Occup Physiol 1986;55:579-84.
51. Holtzhausen LM, Noakes TD, Kroning B, et al. Clinical and biochemical characteristics of collapsed ultra-marathon runners. Med Sci Sports Exerc 1994;26:1095-101.

52. Kratz A, Lewandrowski KB, Siegel AJ, et al. Effect of marathon running on hematologic and biochemical laboratory parameters, including cardiac markers. Am J Clin Pathol 2002;118:856-63.

53. Reid SA, Speedy DB, Thompson JM, et al. Study of hematological and biochemical parameters in runners completing a standard marathon. Clin J Sport Med 2004;14:344-53.

54. Mingels A, Jacobs L, Kleijnen V, et al. Cystatin $C$ a marker for renal function after exercise. Int J Sports Med 2009;30:668-71.

55. McCullough PA, Chinnaiyan KM, Gallagher MJ, et al. Changes in renal markers and acute kidney injury after marathon running. Nephrology 2011;16:194-9.

56. Mydlík M, Derzsiová K, Bohus B. Renal function abnormalities after marathon run and 16-kilometre long-distance run. Przegl Lek 2012;69:1-4.

57. Borkowski J, Sobiech KA. Protein: creatinine and trypsin inhibitor: creatinine ratios in the urine of marathon runners. Eur $J \mathrm{Appl}$ Physiol Occup Physiol 1990;61:124-7.

58. Nelson PB, Ellis D, Fu F, et al. Fluid and electrolyte balance during a cool weather marathon. Am J Sports Med 1989;17:770-2.

59. Hewing B, Schattke S, Spethmann S, et al. Cardiac and renal function in a large cohort of amateur marathon runners. Cardiovasc Ultrasound 2015;13:13:13.

60. Irving RA, Noakes TD, Burger SC, et al. Plasma volume and renal function during and after ultramarathon running. Med Sci Sports Exerc 1990;22:581-7.

61. Irving RA, Noakes TD, Buck R, et al. Evaluation of renal function and fluid homeostasis during recovery from exercise-induced hyponatremia. J Appl Physiol 1991;70:342-8.

62. Lippi G, Sanchis-Gomar F, Salvagno GL, et al. Variation of serum and urinary neutrophil gelatinase associated lipocalin (NGAL) after strenuous physical exercise. Clin Chem Lab Med 2012;50:1585-9.

63. Hoffman MD, Stuempfle KJ, Fogard K, et al. Urine dipstick analysis for identification of runners susceptible to acute kidney injury following an ultramarathon. J Sports Sci 2013;31:20-31.

64. Noakes TD, Carter JW. Biochemical parameters in athletes before and after having run 160 kilometres. S Afr Med J 1976;50:1562-6.

65. Irving RA, Noakes TD, Raine RI, et al. Transient oliguria with renal tubular dysfunction after a $90 \mathrm{~km}$ running race. Med Sci Sports Exerc 1990;22:756-61.

66. Lipman GS, Krabak BJ, Waite BL, et al. A prospective cohort study of acute kidney injury in multi-stage ultramarathon runners: the Biochemistry in endurance Runner Study (BIERS). Res Sports Med 2014;22:185-92.

67. Hou SK, Chiu YH, Tsai YF, et al. Clinical Impact of Speed Variability to identify Ultramarathon Runners at Risk for acute Kidney Injury. PLoS One 2015;10:e0133146.

68. Christensen DL, Espino D, Infante-Ramírez R, et al. Normalization of elevated cardiac, kidney, and hemolysis plasma markers within $48 \mathrm{~h}$ in Mexican Tarahumara runners following a $78 \mathrm{~km}$ race at moderate altitude. Am J Hum Biol 2014;26:836-43.

69. Dumke CL, Nieman DC, Oley K, et al. Ibuprofen does not affect serum electrolyte concentrations after an ultradistance run. $\mathrm{Br} J$ Sports Med 2007;41:492-6.

70. Lippi G, Schena F, Salvagno GL, et al. Acute variation of estimated glomerular filtration rate following a half-marathon run. Int J Sports Med 2008;29:948-51.

71. Mohseni M, Silvers S, McNeil R, et al. Prevalence of hyponatremia, renal dysfunction, and other electrolyte abnormalities among runners before and after completing a marathon or half marathon. Sports Health 2011;3:145-51.

72. Wharam PC, Speedy DB, Noakes TD, et al. NSAID use increases the risk of developing hyponatremia during an ironman triathlon. Med Sci Sports Exerc 2006;38:618-22.

73. Irving RA, Noakes TD, van Zyl Smit R. Metabolic and renal changes in two athletes during a world 24 hour relay record performance. $\mathrm{Br}$ J Sports Med 1989;23:227-32.

74. Page AJ, Reid SA, Speedy DB, et al. Exercise-associated hyponatremia, renal function, and nonsteroidal antiinflammatory drug use in an ultraendurance mountain run. Clin $J$ Sport Med 2007:17:43-8.

75. Neumayr G, Pfister R, Hoertnagl $\mathrm{H}$, et al. The effect of marathon cycling on renal function. Int $J$ Sports Med 2003;24:131-7.

76. Neumayr G, Pfister R, Hoertnagl $\mathrm{H}$, et al. Renal function and plasma volume following ultramarathon cycling. Int J Sports Med 2005;26:2-8. 
77. Reid SA, King MJ. Serum biochemistry and morbidity among runners presenting for medical care after an Australian mountain ultramarathon. Clin J Sport Med 2007;17:307-10.

78. Schütz UH, Schmidt-Trucksäss A, Knechtle B, et al; The TransEurope FootRace Project. longitudinal data acquisition in a cluster randomized mobile MRI observational cohort study on 44 endurance runners at a 64 -stage $4486 \mathrm{~km}$ transcontinental ultramarathon. BMC Med 2012;10:78

79. Dharnidharka VR, Kwon C, Stevens G. Serum cystatin C is superior to serum creatinine as a marker of kidney function: a metaanalysis. Am J Kidney Dis 2002;40:221-6.

80. Kashani K, Al-Khafaji A, Ardiles T, et al. Discovery and validation of cell cycle arrest biomarkers in human acute kidney injury. Crit Care 2013;17:R25.

81. Bihorac A, Chawla LS, Shaw AD, et al. Validation of cell-cycle arrest biomarkers for acute kidney injury using clinical adjudication. Am J Respir Crit Care Med 2014;189:932-9.

82. Koyner JL, Shaw AD, Chawla LS, et al; Sapphire Investigators. Tissue Inhibitor Metalloproteinase-2 (TIMP-2). IGF-Binding Protein-7 (IGFBP7) Levels Are Associated with Adverse Long-Term Outcomes in Patients with AKI. J Am Soc Nephrol 2015;26:1747-54.

83. Castenfors J, Mossfeldt F, Piscator M. Effect of prolonged heavy exercise on renal function and urinary protein excretion. Acta Physiol Scand 1967;70:194-206.

84. Poortmans JR. Exercise and renal function. Sports Med 1984:1:125-53.

85. Castenfors J. Renal function during prolonged exercise. Ann $N Y$ Acad Sci 1977;301:151-9.

86. Grimby G. Renal clearances during prolonged supine exercise at different loads. Journal of Applied Physiology 1965;20:1294-8.

87. Köhler H. Fluid metabolism in exercise. Kidney Int Supp 1987;21:S93-6.

88. Poortmans JR, Vanderstraeten J. Kidney function during exercise in healthy and diseased humans. an update. Sports Med 1994;18:419-37.

89. Röcker L, Kirsch KA, Heyduck B, et al. Influence of prolonged physical exercise on plasma volume, plasma proteins, electrolytes, and fluid-regulating hormones. Int J Sports Med 1989;10:270-4.

90. Kosunen KJ, Pakarinen AJ. Plasma renin, angiotensin II, and plasma and urinary aldosterone in running exercise. J Appl Physiol 1976;41:26-9.

91. McAllister RM. Adaptations in control of blood flow with training: splanchnic and renal blood flows. Med Sci Sports Exerc 1998;30:375-81.

92. Armstrong RB. Muscle damage and endurance events. Sports Med 1986;3:370-81.

93. Newham DJ, Jones DA, Edwards RH. Large delayed plasma creatine kinase changes after stepping exercise. Muscle Nerve 1983;6:380-5.

94. Noakes TD. Effect of exercise on serum enzyme activities in humans. Sports Med 1987:4:245-67.

95. Brody SL, Wrenn KD, Wilber MM, et al. Predicting the severity of cocaine-associated rhabdomyolysis. Ann Emerg Med 1990;19:1137-43.

96. Ward MM. Factors predictive of acute renal failure in rhabdomyolysis. Arch Intern Med 1988;148:1553-7.

97. Skenderi KP, Kavouras SA, Anastasiou CA, et al. Exertional Rhabdomyolysis during a $246-\mathrm{km}$ continuous running race. Med Sci Sports Exerc 2006;38:1054-7.

98. Demos MA, Gitin EL, Kagen LJ. Exercise myoglobinemia and acute exertional rhabdomyolysis. Arch Intern Med 1974;134:669-73.
99. Bosch X, Poch E, Grau JM. Rhabdomyolysis and acute kidney injury. N Engl J Med 2009;361:62-72.

100. Murray MD, Brater DC. Renal toxicity of the nonsteroidal anti-inflammatory drugs. Annu Rev Pharmacol Toxicol 1993;33:435-65.

101. Kramer HJ, Stinnesbeck B, Klautke G, et al. Interaction of renal prostaglandins with the renin-angiotensin and renal adrenergic nervous systems in healthy subjects during dietary changes in sodium intake. Clin Sci 1985;68:387-93.

102. Stokes JB. Effect of prostaglandin E2 on chloride transport across the rabbit thick ascending limb of Henle. selective inhibitions of the medullary portion. J Clin Invest 1979;64:495-502.

103. Anderson RJ, Berl T, McDonald KD, et al. Evidence for an in vivo antagonism between vasopressin and prostaglandin in the mammalian kidney. J Clin Invest 1975;56:420-6.

104. Whelton A. Nephrotoxicity of nonsteroidal anti-inflammatory drugs: physiologic foundations and clinical implications. Am J Med 1999;106:S13-24.

105. Sedor JR, Davidson EW, Dunn MJ. Effects of nonsteroidal antiinflammatory drugs in healthy subjects. Am J Med 1986;81:58-70.

106. Walker RJ, Fawcett JP, Flannery EM, et al. Indomethacin potentiates exercise-induced reduction in renal hemodynamics in athletes. Med Sci Sports Exerc 1994;26:1302-6.

107. Olsen NV, Jensen NG, Hansen JM, et al. Non-steroidal antiinflammatory drugs and renal response to exercise: a comparison of Indomethacin and nabumetone. Clin Sci 1999;97:457-65.

108. Donnelly AE, Maughan RJ, Whiting PH. Effects of ibuprofen on exercise-induced muscle soreness and indices of muscle damage. Br J Sports Med 1990;24:191-5.

109. Bourgeois J, MacDougall D, MacDonald J, et al. Naproxen does not alter indices of muscle damage in resistance-exercise trained men. Med Sci Sports Exerc 1999;31:4-9.

110. Donnelly AE, McCormick K, Maughan RJ, et al. Effects of a nonsteroidal anti-inflammatory drug on delayed onset muscle soreness and indices of damage. Br J Sports Med 1988;22:35-8.

111. Carter R. 3rd, Cheuvront SN, Williams JO, et al. Epidemiology of hospitalizations and deaths from heat illness in soldiers. Med Sci Sports Exerc 2005;37:1338-44.

112. Pattison ME, Logan JL, Lee SM, et al. Exertional heat stroke and acute renal failure in a young woman. Am J Kidney Dis 1988;11:184-7.

113. Holman ND, Schneider AJ. Multi-organ damage in exertional heat stroke. Neth J Med 1989;35:38-43.

114. Roberts WO. Exertional heat stroke during a cool weather marathon: a case study. Med Sci Sports Exerc 2006;38:1197-203.

115. Walter E, Venn R, Stevenson T. Exertional Heat Stroke - The Athlete's Nemesis. Journal of the Intensive Care Society 2012;13:304-8

116. Bouchama A, Knochel JP. Heat stroke.N Engl $J$ Med 2002;346:1978-88.

117. Racinais S, Alonso JM, Coutts AJ, et al. Consensus recommendations on training and competing in the heat. Sports Med 2015;45:925-38.

118. Ishikawa I. Acute renal failure with severe loin pain and patchy renal ischemia after anaerobic exercise in patients with or without renal hypouricemia. Nephron 2002;91:559-70.

119. Izumi M, Yokoyama K, Yamauchi A, et al. A young man with acute renal failure and severe loin pain. Nephron 1997;76:215-7.

120. Han JS, Kim YG, Kim S, et al. Bone scintigraphy in acute renal failure with severe loin pain and patchy renal vasoconstriction. Nephron 1991;59:254-60.

121. Mehta RL, Kellum JA, Shah SV, et al; Acute Kidney Injury Network. Acute Kidney Injury Network: report of an initiative to improve outcomes in acute kidney injury. Crit Care 2007;11:R31. 